\title{
Assessment of Hydration Status at a Single Time Point in Athletes
}

\author{
Konrad Witek ${ }^{1 *}$, Agata Gontarek ${ }^{2}$, Dariusz Turowski ${ }^{1}$, Sylwia Lewandowska-Pachecka ${ }^{3}$ and Be- \\ nedykt H Opaszowski ${ }^{1}$ \\ ${ }^{1}$ Biochemistry Department, Institute of Sport-National Research Institute, Poland \\ ${ }^{2}$ Endocrinology Department, Institute of Sport-National Research Institute, Poland \\ ${ }^{3}$ Faculty of Pharmacy with the Laboratory Medicine Division, Medical University of Warsaw, Poland \\ *Corresponding author: Konrad Witek, Biochemistry Department, Institute of Sport-National Research Institute, Poland
}

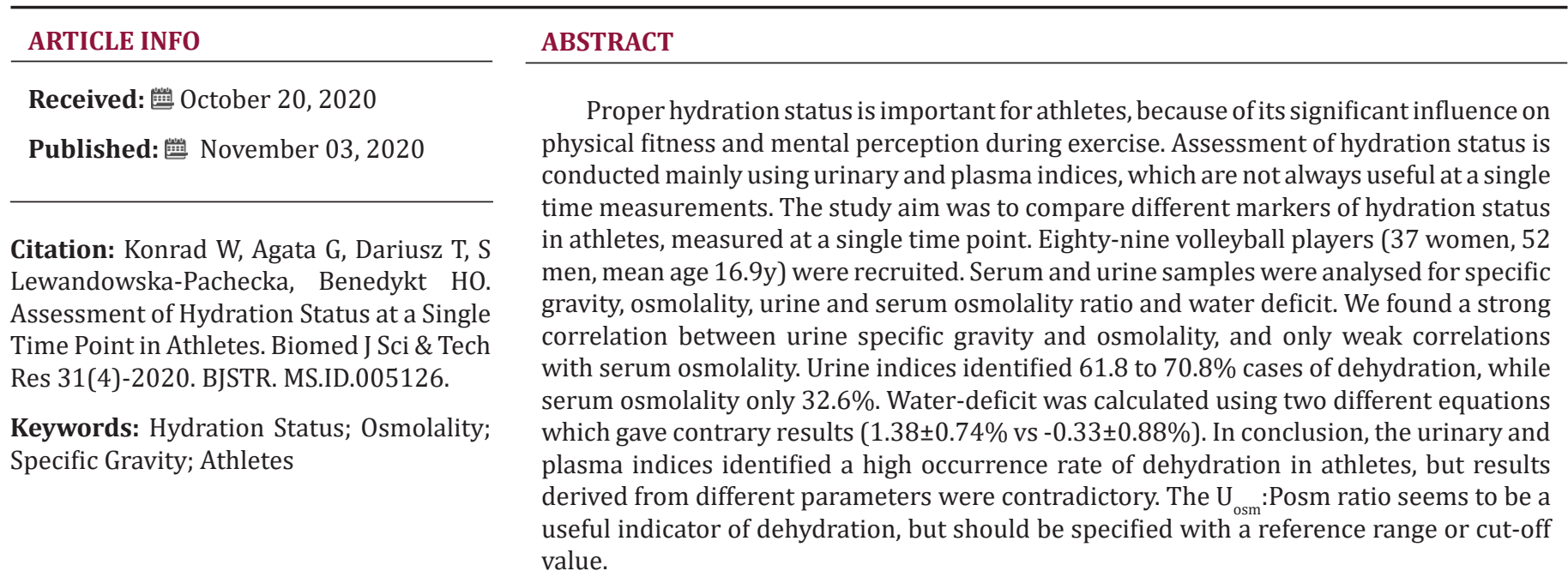

\section{Introduction}

Maintaining the correct water balance is one of the most dynamic and important process in human body [1]. This is especially important for athletes, because dehydration can have a negative influence on physical and cognitive performance [2,3]. As such, monitoring athlete hydration status is crucial for optimising performance during training sessions and competitions. The assessment of hydration is mainly based on urine and blood indices, with no consensus regarding the "gold standard" in dehydration markers [2]. One of the most popular markers is plasma osmolality, which reflects intracellular dehydration [3]. Other common indices are urine osmolality and urine specific gravity. Shirreffs [4] concluded that urinary markers are more sensitive indicators of dehydration, but they may have a delay in the reaction. Urine measurements seems to be secondary to plasma osmolality changes [5]. Searching for better indicators of dehydration, researchers have tested composite measures calculated on the basis of blood or urine tests. For example, Cheuvront et al. [6] tested a series of water-deficit equations, and they found significant improvements after replacement in the equation of sodium to plasma osmolality. Likewise, Armstrong et al. [7] suggested that urine:plasma osmolality ratio could be good indicator of hydration status, measured at a single time point.

Parallel to the search of reliable dehydration markers, studies have investigated the utility of identifying cut-off values. The physiological regulation of plasma osmolality makes that normal values vary about $1-2 \%$ from value of $287 \mathrm{mOsm} / \mathrm{kg}$ in wellhydrated individuals [8]. Based on the small deviation, a cut-off of $290 \mathrm{mOsm} / \mathrm{kg}$ would seem suitable for classifying subjects as being either euhydrated or dehydrated [9]. Manz and Wentz [7] suggested cut-off value for urinary osmolality of $830 \mathrm{mOsm} / \mathrm{kg}$. Baron et al. [8] 
suggest that osmolality over $800 \mathrm{mOsm} / \mathrm{kg}$ is a more appropriate threshold for differentiation between euhydrated and slightly dehydrated status. In the case of urine specific gravity, a number of studies indicate cut-off values of 1.020-1.025 for the upper range of euhydrated state [10-12]. Given the discrepancies, the aim of this study was to compare different markers of hydration status in athletes, measured at a single time point.

\section{Materials and Methods}

Eighty-nine volleyball players (37 women and 52 men, anthropometric data in Table 1) participated in this study. Testing was conducted in a laboratory at the Department of Biochemistry, Institute of Sport-National Research Institute in Warsaw, Poland. This study was approved by the Ethical Research Committee at the Institute of Sport-NRI in Warsaw. Participants were arrived at laboratory between 7:00 and 9:00am. The players were at the beginning of the league season and had two training sessions daily. Venous blood and urea samples were collected after arrival on an empty stomach and transferred to the laboratory within 1 hour of collection.

Table 1: Anthropometric characteristic of the study group (mean \pm SD).

\begin{tabular}{|c|c|c|c|c|c|}
\hline \multirow{2}{*}{ Sex } & \multirow{2}{*}{$\mathbf{n}$} & Age & Body mass & Body height & \multirow{2}{*}{ BMI } \\
\cline { 3 - 5 } & & {$[$ years] } & {$[\mathbf{k g}]$} & {$[\mathbf{m}]$} & \\
\hline Female & 37 & $16.4 \pm 1.4$ & $67.7 \pm 7.6$ & $182.5 \pm 6.7$ & $20.3 \pm 2.2$ \\
\hline Male & 52 & $17.4 \pm 0.9$ & $83.9 \pm 8.0$ & $195.5 \pm 6.4$ & $22.0 \pm 1.9$ \\
\hline All & 89 & $16.9 \pm 1.2$ & $77.2 \pm 11.2$ & $190.1 \pm 9.1$ & $21.3 \pm 2.2$ \\
\hline
\end{tabular}

Whole blood was collected into different tubes (Vacuette vacuum system tubes, Greiner bio-One, Kremsmünster, Austria): for glucose measurement containing sodium fluoride, for sodium measurement containing lithium heparin, for measurements in serum containing coagulation accelerator (and left to clot for 30 minutes and centrifuged at $2000 \mathrm{~g}$ for 10 minutes). Urine was collected in a sterile urine beaker. Serum $\left(\mathrm{S}_{\text {osm }}\right)$ and urine $\left(\mathrm{U}_{\text {osm }}\right)$ osmolality was measured by freezing point depression method (OS3000 osmometer, Marcel, Zielonka, Poland), Urine Specific Gravity (USG) using a handheld refractometer (Atago PAL-10s, Tokyo, Japan). For further calculations, sodium concentration $\left(\mathrm{Na}^{+}\right)$ was measured in whole blood using ion analyser (pHOx plus $\mathrm{M}$, Nova Biomedical, Waltham, MA, USA), plasma glucose and serum urea concentrations were measured using colorimetric methods with Cobas Integra400 biochemical analyser (Roche Diagnostic, Basel, Switzerland) with original manufacturer reagent kits. Water deficit was calculated by equations [6]:

$$
\begin{aligned}
& \mathrm{WD}_{1}=0.6 \times \text { body mass } \mathrm{x}\left[1-\left(140 \div \mathrm{Na}^{+}\right)\right] \text {, and } \\
& \mathrm{WD}_{2}=0.6 \mathrm{x} \text { body mass } \mathrm{x}\left[1-\left(290 \div \mathrm{S}_{\mathrm{osm}}\right)\right]
\end{aligned}
$$

Additional osmolality variable was computed by the formula:
All assays were completed on the same day. Testing was conducted in a laboratory certified from the Polish Centre for Accreditation (no. AB 946).

\section{Statistical Analyses}

All data are presented as mean \pm SD. The Shapiro-Wilk test was employed to determinate data normality. Because most of the data did not follow a normal distribution, Wilcoxon signed-rank tests was used for a comparison of mean differences. Relationships between variables were also determined using Pearson's correlation coefficient. The level of $p \leq 0.05$ was considered significant. Variables were analysed with Statistica 13 software (TIBCO Software INC., Palo Alto, CA, USA).

\section{Results}

Table 2 shows the measured parameters, and Table 3 shows correlation between them. Significant but weak correlations were observed between $\mathrm{U}_{\mathrm{SG}}$ and $\mathrm{S}_{\text {osm }}$ or $\mathrm{WD}_{2}$. Interestingly, $\mathrm{S}_{\text {osm }}$ strongly correlated with $\mathrm{WD}_{2}$ but there were only weak correlation with $\mathrm{U}_{\text {osm }}: \mathrm{S}_{\text {osm }}$ ratio. Calculated osmolality was significantly higher than measured one, and correlation between them was statistically important but rather weak. We observed statistically significant differences between water deficit equations $W D_{1}$ and $W D_{2}$ but with opposite mean values and weak correlation between them. In approximately half of the athletes (49.3\%) WD results were above $2 \%$, what can be considered as important dehydration, while by $\mathrm{WD}_{2}$ only $1.1 \%$ reached this threshold.

Table 2: Values of measured and calculated parameters

\begin{tabular}{|c|c|c|c|}
\hline & Female & Male & All \\
\hline USG & $1.023 \pm 0.006$ & $1.024 \pm 0.005$ & $1.023 \pm 0.005$ \\
\hline $\begin{array}{c}\mathrm{U}_{\text {osm }} \\
{[\mathrm{mOsm} / \mathrm{kg}]}\end{array}$ & $835.5 \pm 204.8$ & $835.6 \pm 199.9$ & $835.5 \pm 200.8$ \\
\hline $\begin{array}{c}\mathrm{S}_{\text {osm }} \\
{[\mathrm{mOsm} / \mathrm{kg}]}\end{array}$ & $286.4 \pm 6.8$ & $289.1 \pm 4.6$ & $287.9 \pm 5.7^{\#}$ \\
\hline $\begin{array}{c}\text { OSM }_{\text {cal }} \\
{[\mathrm{mOsm} / \mathrm{kg}]}\end{array}$ & $297.6 \pm 5.4$ & $299.6 \pm 4.2$ & $298.8 \pm 4.8^{\#}$ \\
\hline $\mathrm{U}_{\mathrm{osm}}: \mathrm{S}_{\mathrm{osm}}$ ratio & $2.91 \pm 0.70$ & $2.89 \pm 0.68$ & $2.90 \pm 0.69$ \\
\hline $\mathrm{WD}_{1}$ & \multirow{2}{*}{$1.12 \pm 0.72$} & \multirow{2}{*}{$1.56 \pm 0.70$} & \multirow{2}{*}{$1.38 \pm 0.74^{*}$} \\
\hline$[\mathrm{L}]$ & & & \\
\hline $\mathrm{WD}_{2}$ & \multirow{2}{*}{$-0.54 \pm 0.98$} & \multirow{2}{*}{$-0.18 \pm 0.78$} & \multirow{2}{*}{$-0.33 \pm 0.88^{*}$} \\
\hline$[\mathrm{L}]$ & & & \\
\hline
\end{tabular}
(mean \pm SD).

Note: Statistically significant relationships between: \# $\mathrm{S}_{\text {osm }}$ and $\mathrm{OSM}_{\mathrm{cal}}{ }^{*}{ }^{*} \mathrm{WD}_{1}$ and $\mathrm{WD}_{2}(\mathrm{p}<0.05$, Wilcoxon signed-rank test).

There were large discrepancies between numbers of results beyond the adopted cut-off values (Table 4). The highest percentage of athletes with dehydration shows OSM $\mathrm{Cal}_{\text {, }}$ and the lowest $\mathrm{S}_{\mathrm{osm}}$. There were no significant correlation between measured or calculated parameters and the age of the athletes.

$\mathrm{OSM}_{\text {cal }}=2 \times\left[\mathrm{Na}^{+}\right]+[$glucose $]+[$urea $]$ 
Table 3: Values of measured and calculated parameters (mean $\pm S D)$.

\begin{tabular}{|c|c|c|c|c|c|c|c|}
\hline & $\mathbf{U}_{\text {SG }}$ & $\mathbf{U}_{\text {osm }}$ & $\mathbf{S}_{\text {osm }}$ & $\mathbf{O S M}_{\text {cal }}$ & $\mathbf{U}_{\text {osm }} \mathbf{S}_{\text {osm }}$ ratio & $\mathbf{W D}_{\mathbf{1}}$ & $\mathbf{W D}_{2}$ \\
\hline $\mathbf{U}_{\text {SG }}$ & & & & & & \\
\hline $\mathbf{U}_{\text {osm }}$ & $0.971^{*}$ & & & & & \\
\hline $\mathbf{S}_{\text {osm }}$ & $0.293^{*}$ & $0.304^{*}$ & & & & \\
\hline $\mathbf{O S M}_{\text {cal }}$ & 0.16 & 0.191 & $0.235^{*}$ & & & \\
\hline $\mathbf{U}_{\text {osm }}: \mathbf{S}_{\text {osm }}$ ratio & $0.969^{*}$ & $0.997^{*}$ & $0.230^{*}$ & 0.171 & & \\
\hline $\mathbf{W D}_{\mathbf{1}}$ & 0.156 & 0.175 & $0.228^{*}$ & $0.945^{*}$ & 0.156 & & \\
\hline $\mathbf{W D}_{\mathbf{2}}$ & $0.293^{*}$ & $0.307^{*}$ & $0.991^{*}$ & $0.247^{*}$ & $0.233^{*}$ & $0.234^{*}$ & \\
\hline
\end{tabular}

Note: *Statistically significant correlation $(\mathrm{p}<0.05)$.

Table 4: Percentage of results above adopted cut-off values.

\begin{tabular}{|c|c|c|c|c|}
\hline \multirow{2}{*}{ Parameter } & \multirow{2}{*}{$\mathbf{U}_{\text {SG }}$} & $\mathbf{U}_{\text {osm }}$ & $\mathbf{S}_{\text {osm }}$ & OSM $_{\text {cal }}$ \\
\cline { 3 - 5 } & & {$[\mathrm{m0sm} / \mathbf{k g}]$} & {$[\mathrm{mOsm} / \mathbf{k g}]$} & {$[\mathrm{m0sm} / \mathbf{k g}]$} \\
\hline Cut-off value & $1.020^{\mathrm{a}}$ & $800^{\mathrm{b}}$ & $290^{\mathrm{c}}$ & $290^{\mathrm{c}}$ \\
\hline All group [\%] & 70.8 & 61.8 & 32.6 & 94.4 \\
\hline
\end{tabular}

Note: Cut-off values adopted from: a'Sawka et al [14], ' Manz and Wentz [9], 'Kenefick et al [8].

\section{Discussion}

Maintaining proper hydration status is important for athletes, because its impact on physical fitness and mental perception [13]. A common practice in sport is the monitoring of hydration using different biomarkers [14]. Problem of maintaining appropriate hydration status is often studied in disciplines with weight categories, e.g. combat sports [15]. In our study, more than $60 \%$ athletes had results of urine indices above cut-off values, shows dehydration status. Considering serum osmolality, only about one-third of the athletes tested were classified as dehydrated. It is noteworthy that the urine indices identified a similar percentage of euhydrated subjects. The greatest percentage of above cut-off

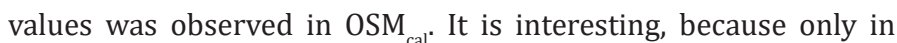
$33.7 \%$ of cases $\left[\mathrm{Na}^{+}\right]$concentration were above $145 \mathrm{mmol} / \mathrm{L}$, what indicates hypertonicity [10]. The results show that the problem of dehydration applies even in those sports that seem less exposed to the occurrence of this phenomenon. One of the most accepted indicators of hydration is plasma osmolality [11]. However, Hamouti et al. [12] suggested that $\mathrm{P}_{\text {osm }}$ is less sensitive after an overnight recovery, and urine specific gravity and osmolality are better under these circumstances. In turn, Cheuvront and Kenefick [16] concluded that urine-based measurements are secondary to changes in $\mathrm{P}_{\text {osm }}$ for detecting dehydration. Shirreffs [4] stated that urinary measures could have a time lag over the short term.

In the current study, we found significant correlations between the urinary indices and Sosm. The percentage of urine results above the adopted cut-off values shows more dehydration cases when compared with data for Sosm. This finding partly confirms the assertion that plasma osmolality could better describe acute changes of hydration status. Although, we measured serum not plasma osmolality, the results are interchangeable [10]. For an accurate assessment of hydration status in sport, it is important to determine appropriate cut-off values for different hydration biomarkers. Unfortunately, wide discrepancies exist in the proposed values for urine osmolality, ranging from $700 \mathrm{mOsm} / \mathrm{kg}$ [17] to above $1000 \mathrm{mOsm} / \mathrm{kg}$ [18]. We adopted a value of $800 \mathrm{m0sm} / \mathrm{kg}$ as a meaningful threshold for differentiation between euhydrated and dehydrated status [7]. In reference to urine specific gravity, most authors apply 1.020 as a cut-off value [11]. Similarly, in case of plasma osmolality, a threshold value of $290 \mathrm{mOsm} / \mathrm{kg}$ is widely accepted.

A lack of consensus around what constitutes the "gold standard" index for assessing hydration status has promoted studies in this area. Armstrong et al. [19] proposed the $U_{\text {osm }}: P_{\text {osm }}$ ratio as a potential hydration biomarker, which can be measured at a single time point. Results obtained in our study are similar to Armstrong's data on a low-volume drinkers group. To our knowledge, there are no specific reference range for this ratio, with values $<1.0$ only indicating the existence of relative water excess. Our data highlight the need to determine reference range or cut-off value for this parameter. Two water-deficit equations were replicated in this work; the most common $\left(\mathrm{WD}_{1}\right)$ and the best according to the authors $\left(\mathrm{WD}_{2}\right)$. We found significant differences and in relation to other obtained results, the $\mathrm{WD}_{1}$ equation seems to be more relevant. The percentage of results above $2 \%$ of water deficit, that is considered as significant for performance [20], were $49.4 \%$ for $\mathrm{WD}_{1}$ and $1.1 \%$ for $\mathrm{WD}_{2}$. Thus, the $\mathrm{WD}_{1}$ results are more convergent with other measures taken in this study. In conclusion, the occurrence frequency of dehydration in the athletes confirms the need for determination of reliable markers of hydration status in different sports disciplines. Urine is a more accessible material for research, but seems to be less effective 
with only single measurements obtained. The $U_{\text {osm }}: P_{\text {osm }}$ ratio seems to be a useful indicator of dehydration status, but should be applied with a specified reference range or cut-off value. In future study should be investigated the need of determining the specific cut-off values for different sports disciplines.

\section{Acknowledgment}

The study was financially supported by Institute of SportNational Research Institute, grant number: 103.04.

\section{References}

1. Jequier E, Constant F (2010) Water as an essential nutrient: the physiological basis of hydration. Eur J Clin Nutr 64(2): 115-123.

2. Armstrong LE (2007) Assessing hydration status: the elusive gold standard. J Am Coll Nutr 26: 575S-584S.

3. Cheuvront SN, Kenefick RW, Charkoudian N, Sawka MN (2013) Physiologic basis for understanding quantitative dehydration assessment. Am J Clin Nutr 97(3): 455-462.

4. Shirreffs SM (2003) Markers of hydration status. Eur J Clin Nutr 57: S6S9.

5. Shoker AS (1994) Application of the clearance concept to hyponatremic and hypernatremic disorders: a phenomenological analysis. Clin Chem 40(7): 1220-1227

6. Cheuvront SN, Kenefick RW, Sollanek KJ, Ely BR, Sawka MN (2013) Water-deficit equation: Systematic analysis and improvement. Am J Clin Nutr 97(1): 79-85.

7. Manz F, Wentz A (2003) 24-h hydration status: parameters, epidemiology and recommendations. Eur J Clin Nutr 57 Suppl 2: S10-S18.

8. Baron S, Courbebaisse M, Lepicard EM, Friedlander G (2015) Assessment of hydration status in a large population. Br J Nutr 113(1): 147-158.

9. Kenefick RW, Ely BR, Cheuvront SN, Palombo LJ, Goodman DA, et al. (2009) Prior heat stress: effect on subsequent 15-min time trial performance in the heat. Med Sci Sports Exerc 41(6): 1311-1316.

\section{ISSN: 2574-1241}

DOI: $10.26717 /$ BJSTR.2020.31.005126

Konrad Witek. Biomed J Sci \& Tech Res

(C) This work is licensed under Creative

Submission Link: https://biomedres.us/submit-manuscript.php
10. Hew-Butler TD, Eskin C, Bickham J, Rusnak M, Vander Meulen M (2018) Dehydration is how you define it: comparison of 318 blood and urine athlete spot checks. BMJ Open Sport Exerc Med 4(1): e000297.

11. Sawka MN, Burke LM, Eichner ER, Maughan RJ, Montain SJ, et al. (2007) American College of Sports Medicine position stand. Exercise and fluid replacement. Med Sci Sports Exerc 39(2): 377-390.

12. Hamouti N, Del Coso J, Mora-Rodriguez R (2013) Comparison between blood and urinary fluid balance indices during dehydrating exercise and the subsequent hypohydration when fluid is not restored. Eur J Appl Physiol 113(3): 611-620.

13. Maughan RJ, Shirreffs SM (2010) Dehydration and rehydration in competative sport. Scand J Med Sci Sports 20: 40-47.

14. Lee EC, Fragala MS, Kavouras SA, Queen RM, Pryor JL, et al. (2017) Biomarkers in sports and exercise: tracking health, performance, and recovery in athletes. J Strength Cond Res 31(10): 2930-2937.

15.Zubac D, Marusic U, Karninčič H (2016) Hydration Status Assessment Techniques and Their Applicability Among Olympic Combat Sports Athletes. Strength Cond J 38(4): 80-89.

16. Cheuvront SN, Kenefick RW (2013) Comparison between blood and urinary indices for dehydration: A different interpretation. Eur J Appl Physiol 113(8): 2167-2168.

17. Cleary MA, Hetzler RK, Wasson D, Wages JJ, Stickley C, et al. (2012) Hydration behaviors before and after an educational and prescribed hydration intervention in adolescent athletes. J Athl Train 47(3): 273281.

18. Armstrong LE, Maresh CM, Castellani JW, Bergeron MF, Kenefick RW, et al. (1994) Urinary indices of hydration status. Int J Sport Nutr 4(3): 265279

19. Armstrong LE, Johnson EC, Munoz CX, Le Bellego L, Klein A, et al. (2013) Evaluation of Uosm: Posm ratio as a hydration biomarker in free-living, healthy young women. Eur J Clin Nutr 67(9): 934-938.

20. Adan A (2012) Cognitive performance and dehydration. J Am Coll Nutr 31(2): 71-78.

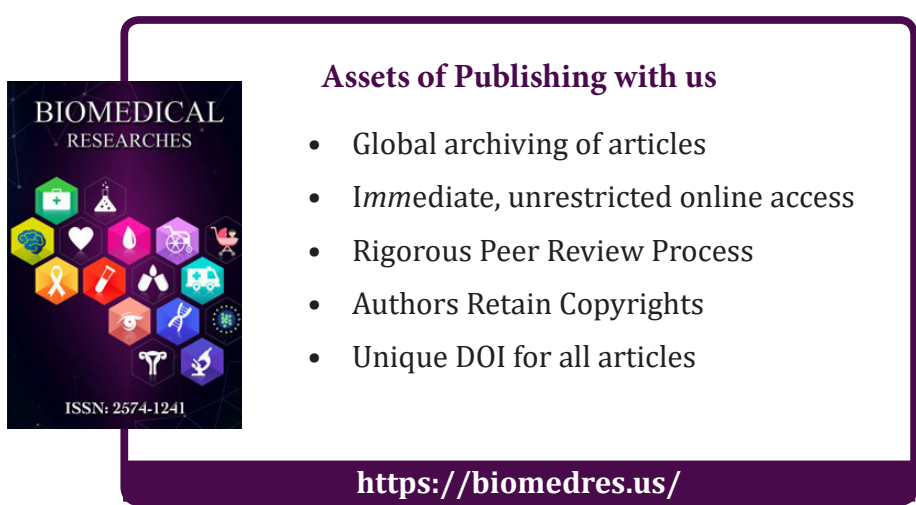

